\title{
Comparative proteomic analysis of the ribosomes in 5-fluorouracil resistance of a human colon cancer cell line using the radical-free and highly reducing method of two-dimensional polyacrylamide gel electrophoresis
}

\author{
KOSEI KIMURA ${ }^{1}$, AKIRA WADA ${ }^{2,4}$, MASAMI UETA ${ }^{2,4}$, AKIHIKO OGATA $^{1}$, SATORU TANAKA $^{1}$, \\ AKIKO SAKAI $^{3}$, HIDEJI YOSHIDA ${ }^{2}$, HIDEO FUSHITANI $^{1}$, AKIKO MIYAMOTO $^{1}$, \\ MASAKAZU FUKUSHIMA ${ }^{5}$, TOSHIO UCHIUMI ${ }^{6}$ and NOBUHIKO TANIGAWA ${ }^{1}$
}

\begin{abstract}
Departments of ${ }^{1}$ General and Gastroenterological Surgery, ${ }^{2}$ Physics, and ${ }^{3}$ Chemistry, Osaka Medical College, 2-7 Daigaku-machi, Takatsuki City, Osaka 569-8686; ${ }^{4}$ Yoshida Biological Laboratory, 11-1 Takehanasotoda-cho, Yamashina-ku, Kyoto 607-8081; ${ }^{5}$ Tokushima Research Center, Taiho Pharmaceutical Co., 224-2 Hiraishi-ebisuno, Kawauchi, Tokushima 771-0194; ${ }^{6}$ Department of Biology, Faculty of Science, Niigata University, Niigata 950-2181, Japan
\end{abstract}

Received April 30, 2010; Accepted June 21, 2010

DOI: 10.3892/ijo_00000778

\begin{abstract}
Many auxiliary functions of ribosomal proteins ( $r$-proteins) have received considerable attention in recent years. However, human r-proteins have hardly been examined by proteomic analysis. In this study, we isolated ribosomal particles and subsequently compared the proteome of r-proteins between the DLD-1 human colon cancer cell line and its 5fluorouracil (5-FU)-resistant sub-line, DLD-1/5-FU, using the radical-free and highly reducing method of two-dimensional polyacrylamide gel electrophoresis, which has a superior ability to separate basic proteins, and we discuss the role of r-proteins in 5-FU resistance. Densitometric analysis was performed to quantify modulated proteins, and protein spots showing significant changes were identified by employing matrix-assisted laser desorption/ionization time-of-flight/timeof-flight mass spectrometry. Three basic proteins (L15, L37 and prohibitin) which were significantly modulated between DLD-1 and DLD-1/5-FU were identified. Two proteins, L15 and L37, showed down-regulated expression in DLD-1/5-FU in comparison to DLD-1. Prohibitin, which is not an r-protein and is known to be localized in the mitochondria, showed up-regulated expression in DLD-1/5-FU. These 3 proteins may be related to 5-FU resistance.
\end{abstract}

Correspondence to: Dr Nobuhiko Tanigawa, Department of General and Gastroenterological Surgery, Osaka Medical College, 2-7 Daigaku-machi, Takatsuki City, Osaka 569-8686, Japan E-mail: sur001@poh.osaka-med.ac.jp

Key words: colon cancer, 5-FU, proteome, ribosome, RFHR 2-D PAGE

\section{Introduction}

The ribosome is a signature component involved in the process of protein biosynthesis in all living cells. It is built up of 3-4 rRNAs and 60-80 ribosomal proteins (r-proteins). It has been believed that the ribosome is composed of an equimolar quantity of all rRNA and r-proteins irrespective of the cell condition (1). However, regulation of the transcriptional activity of the r-protein genes in different human tissues appears to be less regulated than previously reported (2). It is therefore interesting to examine relative amounts of the translated ribosomal proteins and their changes in cell conditions.

Several reports have suggested the role of r-proteins in tumor drug resistance. For example, r-protein S3a has been reported to enhance the responses of acute myeloblastic leukemia blasts to cytosine arabinoside and doxorubicin (3), and the r-protein L6 has been reported to regulate multidrug resistance in gastric cancer cells by suppressing drug-induced apoptosis (4). However, these recent studies have analyzed either the level of the r-protein gene or limited r-proteins using these antibodies, and no study exhaustively examining all human r-proteins has been performed.

Although an immobilized pH gradient (IPG) method is mainly used for two-dimensional polyacrylamide gel electrophoresis (2-D PAGE) proteomic analysis, this procedure cannot sufficiently separate basic proteins with isoelectric points (pI) greater than $\mathrm{pH} 10$. The $\mathrm{pI}$ of most human r-proteins is greater than $\mathrm{pH} 10$, therefore, human r-proteins have hardly been examined by IPG method.

Radical-free and highly reducing (RFHR) 2-D PAGE is not limited by the $\mathrm{pI}$ of a protein, and basic proteins can be sufficiently separated by this method as well as neutral and acidic proteins. We previously utilized this procedure for the analysis of Escherichia coli (E.coli) r-proteins, and discovered two new r-proteins, L35 and L36 $(5,6)$. 
5-fluorouracil (5-FU) is a key drug which is widely used for chemotherapy in patients with colon cancer, and the development of resistance to $5-\mathrm{FU}$ is one of the most important problems in treating colon cancer. To investigate 5-FU resistance in colon cancer, we previously performed proteomic analysis of the total basic proteins in a human colon cancer cell line, DLD-1, and its 5-FU-resistant line, DLD-1/5-FU, using RFHR 2-D PAGE, and identified six proteins that were significantly modulated between these lines.

In this study, we focused on the role of ribosomes in 5-FU resistance; therefore, we compared the proteome of r-proteins which constitute the ribosomes of DLD-1 with that of DLD1/5-FU using this RFHR 2-D PAGE method.

\section{Materials and methods}

Cell lines and in vitro cytotoxicity assay. The human colon cancer cell line DLD-1 and its 5-FU resistant sub-cell line, DLD-1/5-FU, were obtained from Taiho Pharmaceutical. These cell lines were previously characterized in our laboratory (7). In brief, a colorimetric assay using the tetrazolium salt 3-(4,5dimethylthiazol-2-yl)-2,5-diphenyltetrazolium bromide (MTT) was used to assess the suppression of cell proliferation by 5-FU (8), and cells were cultured in RPMI-1640 supplemented with $10 \% \mathrm{FBS}$ at $37^{\circ} \mathrm{C}$ with $5 \% \mathrm{CO}_{2}$ in a humidified atmosphere.

Calculation of doubling times and detection of apoptosis. We evaluated the doubling times and percentage of apoptotic cells in DLD-1 and DLD-1/5-FU for the analysis of cellular proliferation and apoptosis of these cell lines. Doubling times for each cell line were calculated by logarithmic transformation of the cell counts $96 \mathrm{~h}$ apart using the MTT assay method six times. Apoptosis was evaluated four times by labeling DNA breaks using a TUNEL assay (Apo-Direct kit, Pharmingen, San Diego, CA, USA), as described by the manufacturer. In brief, DLD-1 and DLD-1/5-FU were incubated with 15 and $150 \mu \mathrm{M} 5$-FU for $96 \mathrm{~h}$, respectively. Ethanol-fixed cells were washed twice with wash buffer, and supernatant was discharged by centrifugation. Freshly prepared DNA-labeling solution (containing TdT and FITC-dUTP) was added to the cell pellet and incubated for $4 \mathrm{~h}$ at $37^{\circ} \mathrm{C}$ with occasional shaking. Cells were washed again, and then resuspended in staining solution containing PI and RNase. Cells were incubated for $30 \mathrm{~min}$ at room temperature and immediately analyzed using a FACSAria cytometer (Becton-Dickinson, San Jose, CA, USA). The percentage of green fluorescentpositive cells with DNA strand breaks was calculated using the LYSIS II or CellQuest software (Becton-Dickinson).

Protein preparation. For protein preparation, 5 sheets in a $150-\mathrm{cm}^{2}$ flask (80\% confluent) of DLD-1 and DLD-1/5-FU were used, respectively. High-salt washed ribosomes (HSRb) were prepared from the cell extract, essentially according to the method of Madjar with some modifications (9). Briefly, the cells in 5 sheets in a $150 \mathrm{~cm}^{2}$ flask were suspended in $1.5 \mathrm{ml}$ of cold buffer A ( $0.25 \mathrm{M}$ sucrose, $25 \mathrm{mM} \mathrm{KCl}, 5 \mathrm{mM}$ $\mathrm{MgCl}_{2}$, and $50 \mathrm{mM}$ Tris-HCl, $\mathrm{pH} 7.4$ ) and slowly stirred with a Vortex while adding $70 \mu \mathrm{l}$ of the $20 \%$ NP-40 solution, and were kept on ice for $10 \mathrm{~min}$. Cell suspensions were layered on top of $1 \mathrm{ml}$ of $1 \mathrm{M}$ sucrose buffer A (1 M sucrose, $25 \mathrm{mM} \mathrm{KCl}$, $5 \mathrm{mM} \mathrm{MgCl}_{2}$, and $50 \mathrm{mM}$ Tris-HCl, $\mathrm{pH}$ 7.4) and centrifuged at $800 \mathrm{~g}$ for $15 \mathrm{~min}$ to spin down the nuclei. Postnuclear supernatants were layered on top of $1 \mathrm{ml}$ of $1 \mathrm{M}$ sucrose buffer $\mathrm{A}$ and centrifuged at $12,500 \mathrm{~g}$ for $15 \mathrm{~min}$ to spin down the mitochondria. Postmitochondrial supernatants were layered on top of $3 \mathrm{ml}$ of $1 \mathrm{M}$ sucrose buffer A and ultracentrifuged at $275,000 \mathrm{~g}$ for $4 \mathrm{~h}$ to spin down crude ribosomes (CR). CR were resuspended in $3 \mathrm{ml}$ of cold buffer $\mathrm{B}(0.25 \mathrm{M}$ sucrose, $0.5 \mathrm{M} \mathrm{KCl}, 5 \mathrm{mM} \mathrm{MgCl}_{2}$, and $50 \mathrm{mM}$ Tris- $\mathrm{HCl}$, $\mathrm{pH}$ 7.4), were layered on top of $3 \mathrm{ml}$ of $1 \mathrm{M}$ sucrose buffer $\mathrm{B}$ ( $1 \mathrm{M}$ sucrose, $0.5 \mathrm{M} \mathrm{KCl}, 5 \mathrm{mM} \mathrm{MgCl}$, and $50 \mathrm{mM}$ Tris- $\mathrm{HCl}$, $\mathrm{pH}$ 7.4), and ultracentrifuged at $275,000 \mathrm{~g}$ for $4 \mathrm{~h}$ to spin down HSRb. R-proteins of HSRb fractions were extracted by the acetic acid method (10). After dialysis against $2 \%$ acetic acid at least five times, the proteins were lyophilized, and stored at $-80^{\circ} \mathrm{C}$ until use.

Ribosome profiling. HSRb were suspended in cold buffer A, layered onto a 5-20\% linear sucrose gradient in buffer A, and centrifuged in a Beckman SW40Ti rotor at 40,000 rpm for $90 \mathrm{~min}$. Ribosome profiles in the gradients were monitored by absorbance at $260 \mathrm{~nm}$ with a UV spectrophotometer (Shimadzu-UV180).

Two dimensional electrophoresis (2-D PAGE) and image analysis. The extracted proteins of HSRb were analyzed by RFHR 2-D PAGE as previously described, with some modifications $(5-7,11)$. The amount of proteins applied was $\sim 1 \mathrm{mg}$ per gel. Gels were stained with Coomassie brilliant blue (CBB) G-250 (Nacalai Tesque, Kyoto, Japan). The gels were scanned with a GS-800 Calibrated Densitometer for differential analysis, using PDQuest ${ }^{\mathrm{TM}}$ version 7.1. software (Bio-Rad Laboratories Inc.). In addition, the gel images were analyzed using the Quantity One ${ }^{\mathrm{TM}}$ version 4.5.0. software program (Bio-Rad Laboratories Inc.). For each gel, spot detection, area calculation, and background subtraction were conducted, and 11 unmodulated spots on each gel (identified as r-proteins S4, S5, S14, S17, S26, L8, L10, L17, L31, L35, and L35a in SwissProt) were used as internal controls. The detection of changes in protein maps between the two cell lines was confirmed by visual inspection. The spots were considered to be significantly up- (or down-) regulated if the corresponding volumes showed an increase (or decrease) by a factor of at least two between DLD-1 (P) and DLD-1/5-FU (R). R/P that is the ratio of modulation for each protein was calculated. For each of the cell lines, 6 lysates (from 6 independent cultures) were analyzed.

In-gel digestion. The protein spots were excised for digestion with sequence-grade modified trypsin (Promega) or lysyl endopeptidase Lys-C (Wako Purified Reagent) employing the following procedures. The gel pieces were destained by incubation in $25 \mathrm{mM}$ ammonium bicarbonate and $30 \%$ acetonitrile for $10 \mathrm{~min}$. For reductive alkylation, gels dehydrated with $100 \%$ acetonitrile for $10 \mathrm{~min}$ at room temperature were incubated for $45 \mathrm{~min}$ at $55^{\circ} \mathrm{C}$ in $50 \mu 1$ of $10 \mathrm{mM}$ dithiothreitol and $25 \mathrm{mM}$ ammonium bicarbonate, followed by replacement of the dithiothreitol solution with $50 \mu 1$ of $50 \mathrm{mM}$ iodoacetamide and $25 \mathrm{mM}$ ammonium bicarbonate and incubation for $30 \mathrm{~min}$ at room temperature in the dark. Gel pieces were 
Table I. $\mathrm{IC}_{50}{ }^{\mathrm{a}}$ values for 5-FU and doubling times of DLD-1 and DLD-1/5-FU.

\begin{tabular}{lrr}
\hline & \multicolumn{1}{c}{ DLD-1 } & DLD-1/5-FU \\
\hline $\mathrm{IC}_{50}(\mu \mathrm{M})$ & $7.02 \pm 1.02$ & $74.14 \pm 4.71$ \\
Doubling time (h) & $19.55 \pm 1.28$ & $37.17 \pm 4.66$
\end{tabular}

${ }^{\mathrm{a}} \mathrm{IC}_{50}$ is defined as the drug concentration that produced a $50 \%$ reduction in $540-\mathrm{nm}$ absorbance compared with untreated controls in MTT assays.

washed with 5\% acetic acid and 50\% methanol, dehydrated in $100 \%$ acetonitrile, and completely dried in a SpeedVac device. Dried pieces were rehydrated for $30 \mathrm{~min}$ at $4^{\circ} \mathrm{C}$ in 8-20 $\mu \mathrm{l}$ of a solution of $50 \mathrm{mM}$ ammonium bicarbonate containing 50-100 ng of trypsin or Lys-C. After incubation for $16 \mathrm{~h}$ at $37^{\circ} \mathrm{C}$, peptides were extracted with $0.1 \%$ trifluoroacetic acid in $30 \%$ acetonitrile for $10 \mathrm{~min}$ at room temperature with sonication. The second extraction of the peptides was performed with $0.1 \%$ trifluoroacetic acid in $60 \%$ acetonitrile. The extracts were concentrated and desalted using ZipTip C18 micropipette tips (Millipore Corp.).

Protein identification by mass spectrometry. For identification using the peptide mass fingerprinting (PMF) method, $0.7-\mu 1$ aliquots were deposited on a target plate (Bruker Daltonik $\mathrm{GmbH}$, Bremen, Germany), followed by the deposition of $0.7 \mu \mathrm{l}$ of the matrix $(10 \mathrm{mg} / \mathrm{ml} \alpha$-cyano-4-hydroxycinnamic acid in $50 \%$ acetonitrile and $0.1 \%$ trifluoroacetic acid). The identification of each protein was carried out by employing PMF analysis using matrix-assisted laser desorption/ionization time-of-flight (MALDI-TOF) mass spectrometry (MS) and tandem mass spectrometry (MS/MS) analysis using Ultraflex
(Bruker Daltonik GmbH). The proteins were identified by matching the PMF results with the Swiss-Prot protein database using the Mascot Search engine. Database searches were carried out applying the following parameters: taxonomy, Homo sapiens; enzyme, trypsin or LysC; and allowing one missed cleavage. Carbamidomethylation was selected as a fixed modification, and the oxidation of methionine was allowed as a variable. The peptide and fragment mass tolerances were set at $100 \mathrm{ppm}$ and 0.5 Da, respectively.

Statistical analysis. On the analysis of 5-FU resistance, doubling times, and apoptosis, data are expressed as the mean \pm SD. The Mann-Whitney non-parametric test was used to compare these data, and p-values $<0.05$ were considered significant. Statistical analysis was performed using the SPSS11.0 software package (Chicago, IL, USA). On image analysis, the spots were considered significantly up- (or down-) regulated if the corresponding volumes showed an increase (or decrease) by a factor of at least two.

\section{Results}

5-FU resistance, doubling times, and apoptosis in human colon cancer cell lines. The cells DLD-1 and DLD-1/5-FU were cultured in RPMI-1640 supplemented with 10\% FBS at $37^{\circ} \mathrm{C}$ with $5 \% \mathrm{CO}_{2}$ in a humidified atmosphere. They were compared to each other by using MTT assay. The $\mathrm{IC}_{50}$ values of 5 -FU were $7.02 \pm 1.0$ and $74.1 \pm 4.7 \mu \mathrm{M}$ in DLD- 1 and DLD-1/5-FU cells, respectively $(\mathrm{p}<0.05)(7)$. The doubling times were $19.55 \pm 1.3$ and $37.17 \pm 4.7 \mathrm{~h}$ in DLD-1 and DLD-1/ 5 -FU cells, respectively $(\mathrm{p}<0.05)$ (Table I). The percentages of apoptotic cells were $68.3 \pm 6.6$ and $6.0 \pm 0.5 \%$ in DLD-1 and DLD-1/5-FU cells, respectively $(\mathrm{p}<0.05)$, which were determined by TUNEL assay as described in Materials and methods (Fig. 1).
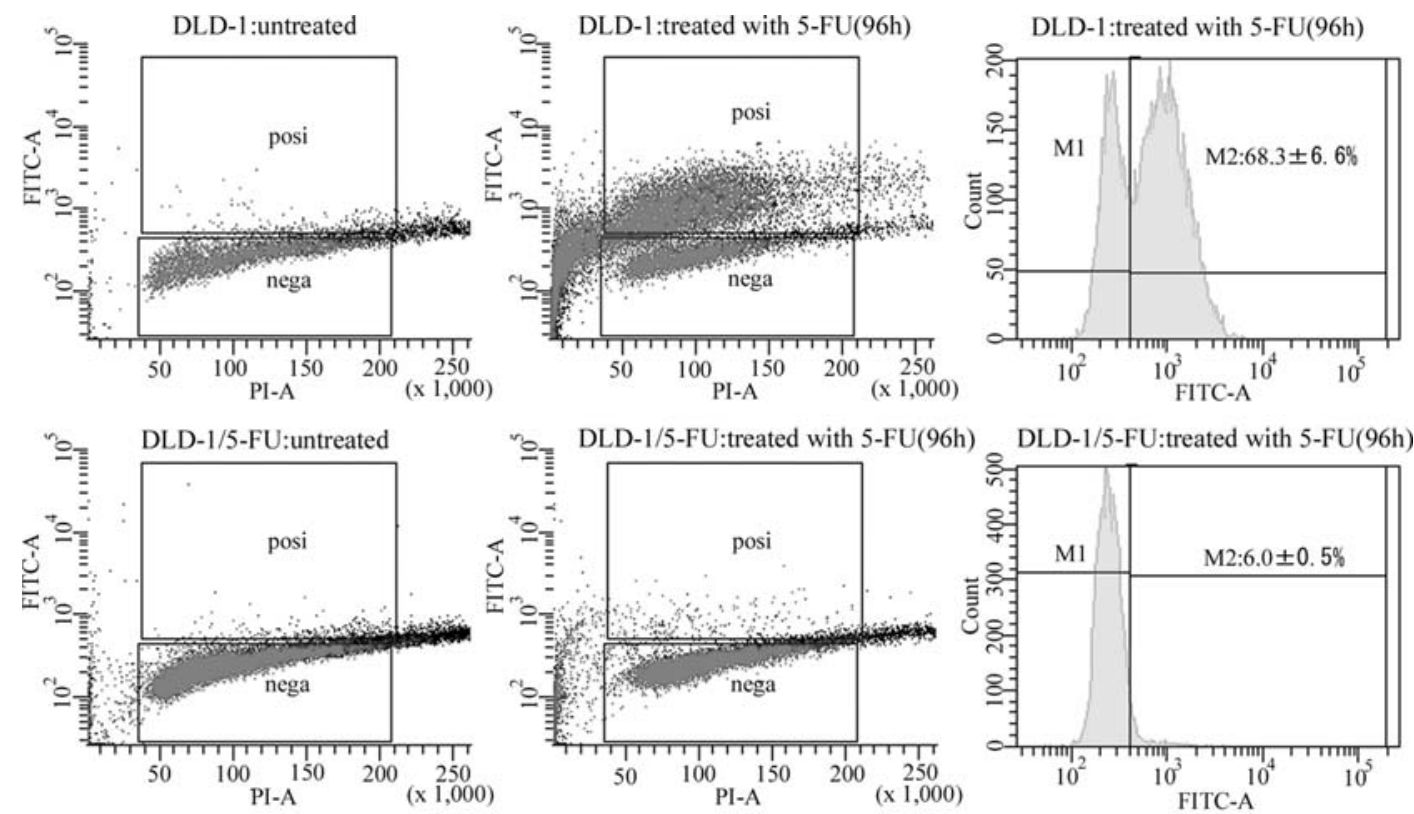

Figure 1. Drug-induced apoptosis of DLD-1 and DLD-1/5-FU. DLD-1 and DLD-1/5-FU were exposed to 5-FU for 96 h. Cells were labeled with both PI (DNA) and FITC (apoptotic cells) using a TUNEL assay (Apo-Direct kit, Pharmingen). Cells in the M1 region were not apoptotic. Cells in the M2 region were apoptotic. The data are shown as the means and SD of four independent experiments. 




Figure 2. Sucrose density gradient centrifugation of E. coli HSRb (70S) and human HSRb (80S).
Sucrose density-gradient centrifugation of ribosomes. Fig. 2 shows the pattern of sucrose density-gradient centrifugation of DLD-1 HSRb and E. coli W3110 HSRb. The symmetric sedimentation patterns of $E$. coli $70 \mathrm{~S}$ and human $80 \mathrm{~S}$ ribosomes suggest that our ribosome samples prepared as described in Materials and methods were more or less homogeneous.

Identification of differentially expressed r-proteins between DLD-1 and DLD-1/5-FU. 2-D patterns of HSRb isolated from DLD-1 and DLD-1/5-FU with high-resolution and reproducibility were obtained. Typical patterns of HSRb of both cell lines are shown in Fig. 3. Three proteins detected as modulated proteins are marked with arrows (Fig. 3A). The relative amounts of these three proteins were determined by using the Quantity One version 4.5.0. software program (Bio-Rad Laboratories Inc.) as described in Materials and methods, and indicated in Fig. 3B. Fig. 3C is a diagram indicating the spot positions and designations for 3 modulated and 11 unmodulated proteins used as internal controls (Fig. 3C). The identification of each protein was carried out by employing PMF analysis, described in Materials and methods. For example, the PMF pattern of L15 and an excised MS/MS pattern obtained by MALDI-TOF/TOF are shown in Fig. 4. Two mass peaks in the PMF pattern, as
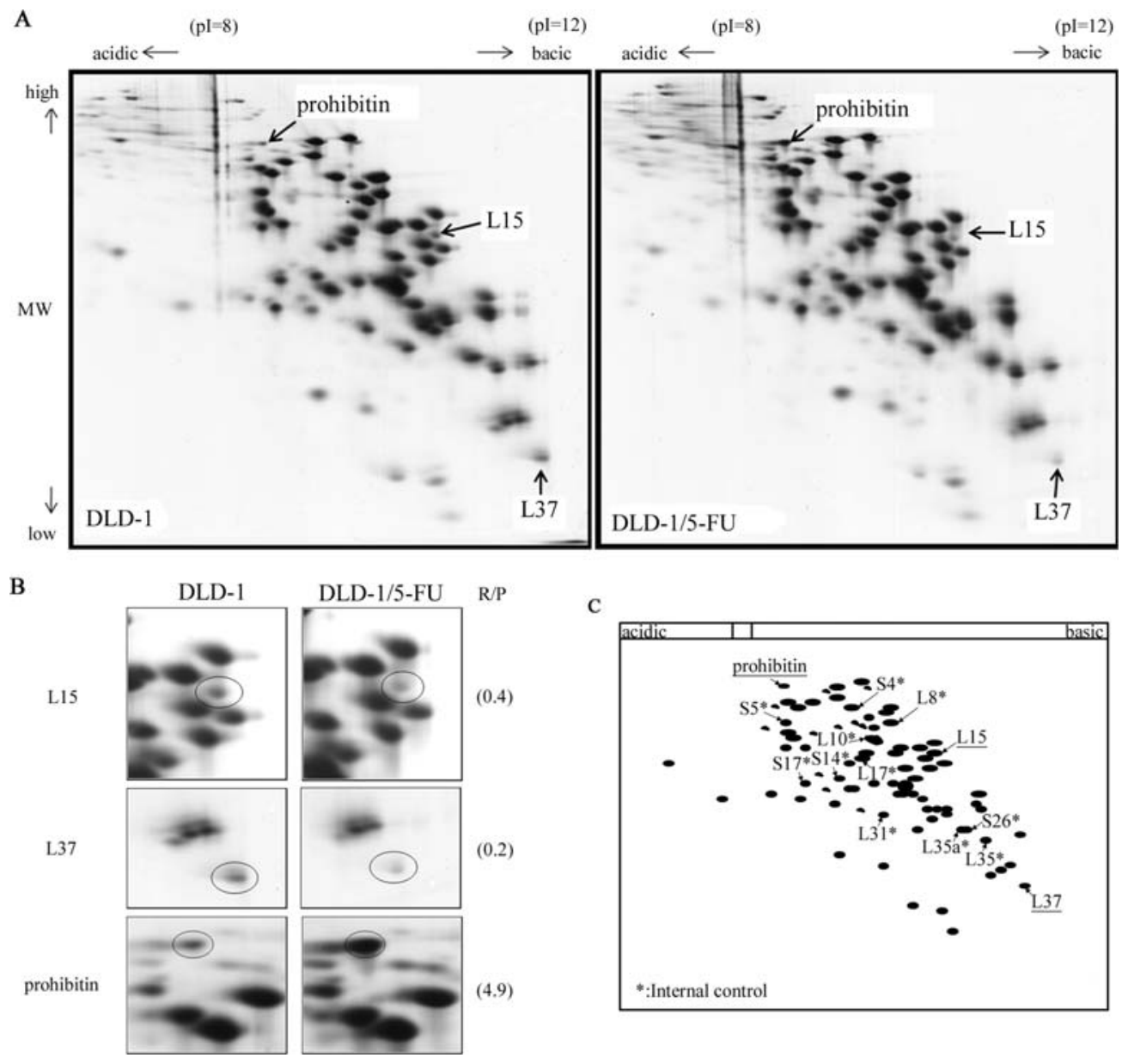

Figure 3. Two-dimensional gel electrophoresis of the ribosomal proteins of DLD-1 and DLD-1/5-FU. (A) The arrows indicate the modulated expression of proteins between DLD-1 and DLD-1/5-FU (L15, L37, and prohibitin). (B) Magnification of these spots. The spots were considered to be significantly up- (or down-) regulated if the corresponding volumes showed an increase (or decrease) by a factor of at least two between DLD-1 (P) and DLD-1/5-FU (R). R/P shows the ratio of modulation for each protein. (C) Diagrammatic representation of ribosomal proteins. The arrows show modulated proteins (under bar) and unmodulated proteins as the internal control $(*)$. 
A

Protein : 60S ribosomal protein L15

Accession No. : RL15_HUMAN

Intensity coverage $58.1 \%$

Sequence coverage $59.3 \%$

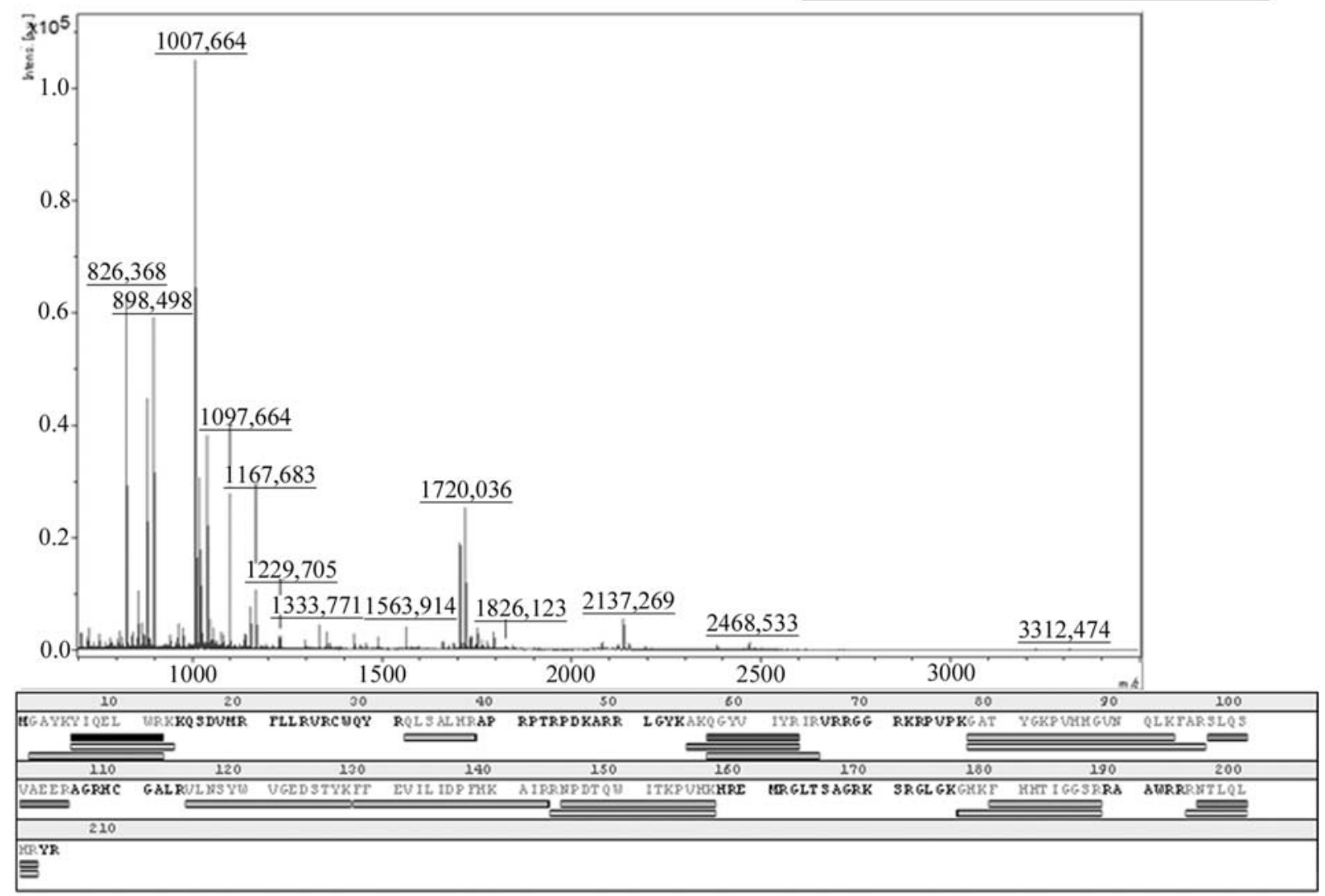

B

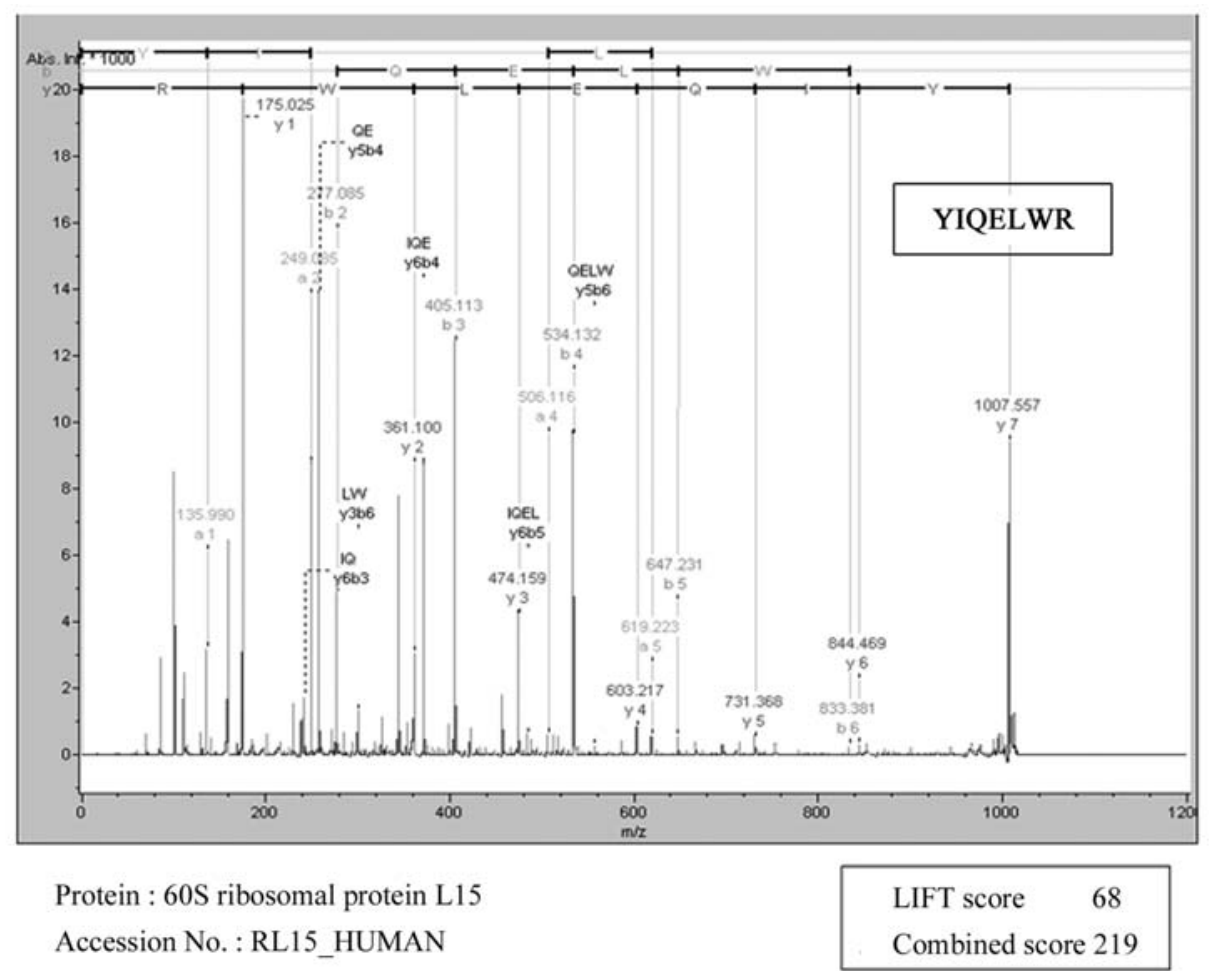

$\begin{array}{llllll}1 & \text { MGAYKYIQEL } & \text { WRKKQSDVMR } & \text { FLLRVRCWQY } & \text { RQLSALHRAP } & \text { RPTRPDKARR } \\ 51 & \text { LGYKAKQGYV } & \text { IYRIRVRRGG } & \text { RKRPVPKGAT } & \text { YGKPVHHGVN } & \text { QLKFARSLQS } \\ 101 & \text { VAEERAGRHC } & \text { GALRVLNSYW } & \text { MESHSHSGGS } & \text { AVGQSRLTAT } & \text { SVSRV }\end{array}$

Figure 4. (A) An example of identification based on PMF patterns of a spot excised from a 2-D gel. (B) An example MS/MS pattern obtained by MALDI TOF/TOF. The result for L15 is shown. Two mass peaks in the PMF pattern as indicated in (A), m/z 1,007,564 and 898,498, were analyzed by MS/MS analysis. 
Table II. MALDI-TOF/TOF MS identification of the modulated and internal control proteins in DLD-1/5-FU.

\begin{tabular}{|c|c|c|c|c|c|c|}
\hline Identification & Accession no. & $\begin{array}{l}\text { Mass } \\
(\mathrm{Da})\end{array}$ & $\mathrm{pI}$ & $\begin{array}{c}\text { Sequence } \\
\text { coverage }(\%)\end{array}$ & MS-MS peak & $\begin{array}{l}\text { Combined } \\
\text { score }\end{array}$ \\
\hline S4 & RS4X_HUMAN & 29,807 & 10.16 & 60.8 & $\begin{array}{l}1,215.750(146-155) \\
1,506.866(199-211)\end{array}$ & 301 \\
\hline S5 & RS5_HUMAN & 23,022 & 9.73 & 41.2 & $\begin{array}{c}900.447(48-55) \\
1,140.645(137-146)\end{array}$ & 151 \\
\hline S14 & RS14_HUMAN & 16,434 & 10.07 & 44.4 & $\begin{array}{l}1,054.592(107-117) \\
1,755.967(126-141)\end{array}$ & 233 \\
\hline S17 & RS17_HUMAN & 15,597 & 9.85 & 83.7 & $\begin{array}{l}1,184.740(15-23) \\
1,201.688(24-33)\end{array}$ & 239 \\
\hline S26 & RS26_HUMAN & 13,292 & 11.01 & 45.2 & $\begin{array}{c}806.467(16-22) \\
1,605.925(101-115)\end{array}$ & 123 \\
\hline L8 & RL8_HUMAN & 28,221 & 11.03 & 48.6 & $\begin{array}{l}1,051.585(61-68) \\
1,076.610(29-37)\end{array}$ & 214 \\
\hline L10 & RL10_HUMAN & 25,044 & 10.11 & 41.1 & $\begin{array}{l}1,018.659(91-98) \\
1,188.731(117-128)\end{array}$ & 190 \\
\hline L15 & RL15_HUMAN & 24,235 & 11.62 & 59.3 & $\begin{array}{c}898.498(57-63) \\
1,007.564(6-12)\end{array}$ & 219 \\
\hline L17 & RL17_HUMAN & 21,611 & 10.18 & 71.7 & $\begin{array}{l}1,057.576(19-27) \\
1,418.707(2-13)\end{array}$ & 311 \\
\hline L31 & RL31_HUMAN & 14,454 & 10.54 & 46.4 & $\begin{array}{r}974.604(76-83) \\
1,173.714(24-32)\end{array}$ & 168 \\
\hline L35 & RL35_HUMAN & 14,543 & 11.04 & 35 & $\begin{array}{l}1,129.785(78-86) \\
1,656.091(57-70)\end{array}$ & 137 \\
\hline $\mathrm{L} 35 \mathrm{a}$ & RL35A_HUMAN & 12,587 & 11.07 & 55.5 & $\begin{array}{l}925.554(9-16) \\
994.568(103-110)\end{array}$ & 94 \\
\hline L37 & RL37_HUMAN & 11,299 & 11.74 & 55.7 & $\begin{array}{l}1,699.919(55-68) \\
2,345.300(69-87)\end{array}$ & 67 \\
\hline Prohibitin & PHB2_HUMAN & 33,276 & 9.83 & 72.9 & $1,177.707(148-157)$ & 315 \\
\hline
\end{tabular}

indicated in Fig. 4A, m/z 1,007.564 and 898.498, were assessed by MS/MS analysis. LIFT scores were 68 (1,007.564) (Fig. 4B) and 58 (898.498). The combined score, representing the total score of PMF and MS/MS (TOF/TOF), was 219. Table II presents the identified proteins with the accession no., theoretical molecular weights, pI, sequence coverage rates, and MS/MS peak, as well as the combined score. Two proteins, L15 and L37, showed down-regulated expression in DLD-1/5-FU in comparison with DLD-1. On the other hand, prohibitin, which is not an r-protein and is known to be localized in mitochondria co-migrated with ribosomal particles during ultracentrifugation, showed up-regulated expression in DLD-1/5-FU.

\section{Discussion}

Many auxiliary functions of r-proteins have received considerable attention in recent years. However, human r-proteins have hardly been examined by 2-D PAGE proteomic analysis because of the high basicity of these proteins. In this study, we compared the proteome of HSRb of DLD-1 with that of DLD-1/5-FU to discuss the role of $\mathrm{r}$-proteins in 5 -FU resistance. We demonstrated that two r-proteins (L15 and L37) showed down-regulated expression in DLD-1/5-FU in comparison with DLD-1, and we also showed an increased doubling time and decreased 5-FU-induced apoptosis in DLD-1/5-FU. Therefore, these 2 r-proteins may be correlated with cellular proliferation and apoptosis, which influences drug sensitivity.

While most r-proteins constitute ribosomal particles with rRNAs, some interact with nonribosomal components of the cell away from this particle. These functions are usually called extraribosomal functions. Wool has reviewed more than 30 examples of r-proteins with extraribosomal functions (12). Several reports have suggested the role of r-proteins in tumor drug resistance. For example, the r-protein S3a, which could be coprecipitated with Bcl-2 from acute myeloblastic leukemia blasts treated with all-trans retinoic acid, has been reported to enhance the response of acute myeloblastic leukemia blasts to cytosine arabinoside and doxorubicin (3). 
The r-protein L6 has been found to be up-regulated in the multidrug-resistant gastric cancer cell line SGC7901/ADR compared to its parental cell line and could regulate drug sensitivity in gastric cancer cells by suppressing drug-induced apoptosis (4). Recently, the up-regulated expression of rprotein L3 was found to have the potential to be related to 5 -FU resistance in our institute (7). Although the extraribosomal functions of these proteins may lead to drug resistance, no molecular mechanisms have been explored in detail.

In this study, we isolated ribosomal particles before analyzing r-proteins, and demonstrated that two r-proteins (L15 and L37) showed down-regulated expression in DLD-1/5-FU on comparison with DLD-1. Therefore, there are more ribosomal particles which lack these two r-proteins in DLD-1/5-FU than in DLD-1. This indicates that the following two hypotheses may be proposed for maintaining chemoresistance in this 5-FU-resistant cell line.

First, the structural change of the ribosome to lose the two proteins might be related to 5-FU resistance in this cell line. The lack of some r-proteins can doom a nascent ribosomal particle, leading to the potential accumulation of other $r$ proteins of ribosomes. A recent report suggests that an accumulation of any of several r-proteins may be related to apoptosis or tumorigenesis (13). We suggest that such an imbalance among r-proteins might be related to cell cycle arrest or apoptosis, which influences drug sensitivity.

Second, the extraribosomal functions of two r-proteins (L15 and L37) might be related to tumor drug resistance in this cell line. In this study, we showed that there are more ribosomal particles which lack these r-proteins in DLD-1/5-FU than in DLD-1. In our previous study in which we performed proteomic analysis of the total basic proteins in these cell lines, L15 and L37 were not modulated (7). Taken together, we suggest that more of these r-proteins in DLD-1/5-FU may be acting extraribosomally, moving away from ribosomal particles, compared to that in DLD-1. Although the biochemical functions of these 2 r-proteins (L15 and L37) remain poorly understood, there have been some recent reports on the functions. Wang et al reported that overexpression of the r-protein L15 is associated with cell proliferation in gastric and esophageal cancer $(14,15)$. They demonstrated that the inhibition of r-protein L15 expression could suppress the proliferation of gastric cancer by in vitro and in vivo assays, and concluded that this protein promotes the growth of gastric cancer (14). Overexpression of the r-protein L37 was identified in colon and prostate cancer and, subsequently, Loging et al showed that expression of this protein gene increases in the presence of the p53 mutant in human tumors (16-18). Thus, these 2 r-proteins may be associated with tumorigenesis. Although no study reported that these $2 \mathrm{r}$ proteins were associated with tumor drug resistance, it has been reported that activating lesions in phosphatidylinositol 3kinase (Pl3K)/AKT/mammalian target of rapamycin (mTOR) signaling not only accelerate tumorigenesis, but also modulate chemosensitivity (19-21). For example, Akt promotes tumorigenesis and drug resistance by disrupting apoptosis, and the blockade of Akt signaling using the mTOR inhibitor rapamycin reverses chemoresistance (20). It has also been reported that L37 contains several putative serine/threonine phosphorylatory sites, suggesting that they may regulate the cascade of r-protein S6 kinases and modulate apoptosis $(22,23)$. Therefore, the $\mathrm{r}$-protein L37 may promote tumorigenesis and drug resistace by disrupting apoptosis. Drug resistance in this 5-FU-resistant cell line may be maintained by the extraribosomal functions of these r-proteins, which are correlated with apoptosis.

In addition, we demonstrated the up-regulated expression of prohibitin on the comparison of DLD-1/5-FU with DLD-1 in this study. Prohibitin has been reported to be localized in the inner mitochondrial membrane, where it forms a large protein complex (24). Many functions of prohibitin have been demonstrated for apoptosis, cell cycle regulation, transmembrane signal transduction, and control of the life span $(24,25)$. Although prohibitin was detected in the 2-D electrophoreseis pattern of r-proteins in this study, it is possible that this protein methodologically co-migrated with ribosomal particles during ultracentrifugation. When HSRb was extracted from the postmitochondrial supernatant with the exception of the fluid close to the mitochondrial pellet, prohibitin could not be detected in the 2-D pattern of r-proteins (data not shown). Recently, Kasashima et al identified that prohibitin regulates the stability of mitochondrial proteins such as HS1-associated protein X-1 and optic atrophy 1, and is involved in anti-apoptosis and regulation of the mitochondrial morphology (26). Further, they reported that prohibitin maintains the organization and copy number of mtDNA through both mitochondrial transcription factor A (TFAM)-dependent and -independent pathways (27). It was shown that TFAM preferentially recognizes cisplatindamaged and oxidized DNA. In addition, increased apoptosis has been observed in cells lacking mitochondrial DNA gene expression, suggesting that TFAM is involved in apoptosis because mitochondria act as a pivotal 'decision-making' center in many types of apoptotic response $(28,29)$. A recent report suggested that the up-regulated expression of TFAM may contribute to the prevention of chemotherapeutic druginduced apoptosis because, in TFAM transfected HeLa cells, the sensitivity of three chemotherapeutic drugs, etoposide, camptothecin, and cisplatin, decreased on comparison with the parental cell line (30). We previously analyzed the proteome of the total basic proteins of DLD-1and DLD-1/5-FU, and demonstrated the up-regulated expression of TFAM in DLD-1/5-FU (7); therefore, this result indicates that chemoresistance in this 5-FU-resistant cell line may be maintained by the protection of mitochondrial DNA through prohibitin and TFAM-dependent pathways.

In conclusion, this study demonstrated the reproducible 2-D patterns of r-proteins isolated from colon cancer cell lines by RFHR 2-D PAGE. We compared the proteome of r-proteins of DLD-1 with that of DLD-1/5-FU, and demonstrated two r-proteins (L15 and L37) within ribosomal particles showing down-regulated expression and prohibitin showing upregulated expression in DLD-1/5-FU on comparison with DLD-1. These three proteins are potential candidates for regulating cellular proliferation and apoptosis, which influences 5-FU drug sensitivity. However, we did not investigate the effect of these three proteins on 5-FU-resistance in DLD-1/ 5-FU. Therefore, further studies to elucidate whether downregulated expressions of the two r-proteins (L15 and L37) 
and up-regulated expression of prohibitin can promote 5-FUresistance in colon cancer should be conducted in the future.

\section{Acknowledgements}

This work was supported in part by a grant-in-aid for Scientific Research from the Japan Society for the Promotion of Science.

\section{References}

1. Mager WH: Control of ribosomal protein gene expression. Biochim Biophys Acta 949: 1-15, 1988.

2. Bortoluzzi S, d'Alessi F, Romualdi C and Danieli GA: Differential expression of genes coding for ribosomal proteins in different human tissues. Bioinformatics 17: 1152-1157, 2001.

3. Hu ZB, Minden MD, McCulloch EA and Stahl J: Regulation of drug sensitivity by ribosomal protein S3a. Blood 95: 1047-1055, 2000 .

4. Du J, Shi Y, Pan Y, Jin X, Liu C, Liu N, Han Q, Lu Y, Qiao T and Fan D: Regulation of multidrug resistance by ribosomal protein 16 in gastric cancer cells. Cancer Biol Ther 4: 242-247, 2005.

5. Wada A: Analysis of Escherichia coli ribosomal proteins by an improved two dimensional gel electrophoresis. I. Detection of four new proteins. J Biochem 100: 1583-1594, 1986.

6. Wada A: Analysis of Escherichia coli ribosomal proteins by an improved two dimensional gel electrophoresis. II. Characterization of four new proteins. J Biochem 100: 1595-1605, 1986.

7. Tanaka S, Sakai A, Kimura K, Yoshida H, Fushitani H, Ogata A, Miyamoto A, Fukushima M, Wada A and Tanigawa N: Proteomic analysis of the basic proteins in 5-fluorouracil resistance of human colon cancer cell line using the radical-free and highly reducing method of two-dimensional polyacrylamide gel electrophoresis. Int J Oncol 33: 361-370, 2008.

8. Carmichael J, De Graff WG, Gazdar AF, Minna JD and Mitchell JB: Evaluation of a tetrazolium-based semiautomated colorimetric assay: assessment of chemosensitivity testing. Cancer Res 47: 936-942, 1987.

9. Madjar JJ: Preparation of ribosomes and ribosomal proteins from cultured cells. In: Cell Biology. Celis JE (ed.) Academic Press Inc., San Diego, pp657-661, 1994.

10. Hardy SJ, Kurland CG, Voynow P and Mora G: The ribosomal proteins of Escherichia coli. I. Purification of the 30 S ribosomal proteins. Biochemistry 8: 2897-2905, 1969.

11. Ueta M, Wada C and Wada A: Formation of $100 \mathrm{~S}$ ribosomes in Staphylococcus aureus by the hibernation promoting factor (HPF) homolog SaHPF. Genes Cells 15: 43-58, 2010

12. Wool IG: Extraribosomal functions of ribosomal proteins. Trends Biochem Sci 21: 164-165, 1996.

13. Warner JR and McIntosh KB: How common are extraribosomal functions of ribosomal proteins? Mol Cell 34: 3-11, 2009.

14. Wang H, Zhao LN, Li KZ, Ling R, Li XJ and Wang L: Overexpression of ribosomal protein L15 is associated with cell proliferation in gastric cancer. BMC Cancer 6: 91, 2006.

15. Wang Q, Yang C, Zhou J, Wang X, Wu M and Liu Z: Cloning and characterization of full-length human ribosomal protein L15 cDNA which was overexpressed in esophageal cancer. Gene 263: 205-209, 2001.
16. Barnard G, Staniunas R, Mori M, Puder M, Jessup M, Steele G and Chen L: Gastric and hepatocellular carcinomas do not overexpress the same ribosomal protein messenger RNAs as colonic carcinoma. Cancer Res 53: 4048-4052, 1993.

17. Vaarala MH, Porvari KS, Kyllönen AP, Mustonen MVJ, Lukkarinen O and Vihko PT: Several genes encoding ribosomal proteins are over-expressed in prostate-cancer cell lines: confirmation of L7a and L37 overexpression in prostate-cancer tissue samples. Int J Cancer 78: 27-32, 1998.

18. Loging WT and Reisman D: Elevated expression of ribosomal protein genes L37, RPP-1, and S2 in the presence of mutant p53. Cancer Epidemiol Biomarkers Prev 8: 1011-1016, 1999.

19. Mills JR, Hippo Y, Robert F, Chen SM, Malian A, Lin CJ, Trojahn U, Wendel HG, Charest AI, Bronson RT, Kogan SC, Nadon R, Housman DE, Lowe SW and Pelletier J: mTORC1 promotes survival through translational control of Mcl-1. Proc Natl Acad Sci USA 105: 10853-10858, 2008.

20. Wendel HG, De Stanchina E, Fridman JS, Malina A, Ray S, Kogan S, Cordon-Cardo C, Pelletier J and Lowe SW: Survival signalling by Akt and eIF4E in oncogenesis and cancer therapy. Nature 428: 332-337, 2004.

21. Wendel HG, Malina A, Zhao Z, Zender L, Kogan SC, Cordon-Cardo C, Pelletier J and Lowe SW: Determinants of sensitivity and resistance to rapamycin-chemotherapy drug combinations in vivo. Cancer Res 66: 7639-7646, 2006.

22. Barnard G, Staniunas R, Puder M, Steele G and Chen L: Human ribosomal protein L37 has motifs predicting serine/threonine phosphorylation and a zinc-finger domain. Biochim Biophys Acta 1218: 425-428, 1994

23. Sturgill TW and Wu J: Recent progress in characterization of protein-kinase cascades for phosphorylation of ribosomal protein S6. Biochim Biophys Acta 1092: 350-357, 1991.

24. Nijtmans LG, Artal SM, Grivell LA and Coates PJ: The mitochondrial PHB complex: roles in mitochondrial respiratory complex assembly, ageing and degenerative disease. Cell Mol Life Sci 59: 143-155, 2002.

25. Fusaro GS and Wang SC: Differential regulation of Rb family proteins and prohibitin during camptothecin-induced apoptosis. Oncogene 21: 4539-4548, 2002.

26. Kasashima K, Ohta E, Kagawa Y and Endo H: Mitochondrial functions and estrogen receptor-dependent nuclear translocation of pleiotropic human prohibitin 2. J Biol Chem 281: 36401-36410, 2006.

27. Kasashima K, Sumitani M, Satoh M and Endo H: Human prohibitin 1 maintains the organization and stability of the mitochondrial nucleoids. Exp Cell Res 314: 988-996, 2008.

28. Wang J, Silva JP, Gustafsson CM, Rustin P and Larsson NG: Increased in vivo apoptosis in cells lacking mitochondrial DNA gene expression. Proc Natl Acad Sci USA 98: 4038-4043, 2001.

29. Green DR and Reed JC: Mitochondria and apoptosis. Science 281: 1309-1312, 1998 .

30. Pastukh V, Shokolenko I, Wang B, Wilson G and Alexeyev M: Human mitochondrial transcription factor A possesses multiple subcellular targeting signals. FEBS J 274: 6488-6499, 2007. 